\title{
Vegetarian Diet and Cardiometabolic Risk among Asian Indians in the United States
}

\author{
Ranjita Misra $\mathbb{D}^{1},{ }^{1}$ Padmini Balagopal, ${ }^{2}$ Sudha Raj $\mathbb{D}^{3},{ }^{3}$ and Thakor G. Patel ${ }^{4}$ \\ ${ }^{1}$ WVU Public Health Training Center, 3313A, Robert C. Byrd Health Science Center, West Virginia University, Morgantown, \\ WV 26506-9190, USA \\ ${ }^{2}$ Clinical Nutritionist, Early Intervention, 1901 JFK Blvd, Philadelphia, PA 19103, USA \\ ${ }^{3}$ Department of Public Health, Food Studies and Nutrition, 562 Falk College, Syracuse, NY 13244, USA \\ ${ }^{4}$ Department of Medicine, Uniformed Services University of the Health Sciences, Bethesda, MD, USA \\ Correspondence should be addressed to Ranjita Misra; ramisra@hsc.wvu.edu
}

Received 3 July 2017; Accepted 22 November 2017; Published 18 February 2018

Academic Editor: Eusebio Chiefari

Copyright (C) 2018 Ranjita Misra et al. This is an open access article distributed under the Creative Commons Attribution License, which permits unrestricted use, distribution, and reproduction in any medium, provided the original work is properly cited.

\begin{abstract}
Research studies have shown that plant-based diets confer cardiovascular and metabolic health benefits. Asian Indians (AIs) in the US (who have often followed plant-based diets) have elevated risk for chronic diseases such as diabetes, metabolic syndrome, and obesity suggesting ethnic vulnerability that imply genetic and/or lifestyle causative links. This study explored the association between this ethnic group and diabetes, obesity, and metabolic syndrome after controlling for demographics, acculturation, family history of diabetes, and lifestyle and clinical risk factors. The sample comprised of 1038 randomly selected adult AIs in seven US sites. Prevalence and metabolic syndrome was estimated, and obesity was calculated using the WHO Asian criteria. Multivariate analysis included multinomial logistic regression. The mean age and length of residency in the US were 47 and 18.5 years, respectively. The majority of respondents were vegetarians (62\%) and educated. A vegetarian lifestyle was associated with females, food label users, respondents with poor/fair current health status, less acculturated, and those who reported their diet had not changed after coming to the US. Vegetarian status was a protective factor and lowered the risk for diabetes but not for metabolic syndrome and obesity in the regression model. Results provide a firm basis for educational programs.
\end{abstract}

\section{Asian Indian Population and Vegetarianism}

According to the 2013 statistics, the US is home to nearly 3.1 million Asian Indians (AIs), the second largest immigrant Asian after the Chinese Americans [1]. They are among the most socioeconomically successful minority ethnic groups but have higher rates of diabetes and cardiovascular disease when compared to the general US population [2-4], despite the consumption of a traditional predominantly plantbased diet (with the inclusion of some dairy). Research has shown that vegetarians have a lower risk for chronic diseases [5]. However, the role of the Asian Indian vegetarian diet in chronic disease incidence in this population remains unclear. Although a couple of recent studies in the subcontinent have examined associations between types of vegetarian diets and chronic diseases using a large, nationally representative sample $[6,7]$, there is paucity of data among immigrant Asian Indians.

Contrary to the popular notion of the homogeneity in socioeconomic, cultural, and health characteristics-the "model minority myth" in the sixties and seventies $[8,9]-$ there is much geographic, linguistic, educational, religious, and socioeconomic heterogeneity in the Asian Indian migrant population today in the US [10,11]. Several studies based on small, nonrandomized convenience samples have now enumerated the high prevalence rates of noncommunicable diseases (NCDs) among Asian Indians in the US [3, 12-14]. More recently, the Diabetes among Indian American (DIA) study nationwide cohort of Asian Indians brought attention to the high prevalence of diabetes, prediabetes, and metabolic syndrome in this immigrant group and to the importance of early interventions to prevent NCDs [12]. 
Global health statistics report acculturative dietary and lifestyle changes (e.g., a reduced consumption of traditional foods; a greater reliance on processed and convenience foods high in fat, sugar, and salt; and reduced physical activity) as primary determinants for the high rates of chronic degenerative diseases and associated complications in various ethnic populations, including urban and migrant AIs regardless of geographic location $[9,15]$. Rapid socioeconomic developments, a changing food system [16], and migration-related transitions in nutrition, dietary practices, and lifestyles [17] are cited as determinants for these changes. In addition, genetic polymorphisms in AIs [18] and the influence of early maternal/fetal nutrition on body fat [19] are also noted as increasing this chronic disease risk. The well-characterized "South Asian phenotype" [20] equated with metabolic syndrome points to lower adiponectin, higher nonesterified fatty acids and C-reactive protein levels, increased insulin resistance, greater abdominal obesity at a lower body weight, and higher lipoprotein "a" levels that are noted to further accentuate these dramatic shifts in the health status of AIs. The "atherogenic dyslipidemic profile" of this phenotype, well noted in AIs, is implicated in the higher cardiovascular risk, that is, higher concentrations of LDL, hypertriglyceridemia, small dense LDL particles, and lower HDL as well as the preponderance of small, dense dysfunctional proinflammatory HDL-c particles [21]. This unique dyslipidemic profile of AIs coupled with high incidence of insulin resistance is shown to be strongly associated with type 2 diabetes and cardiovascular risk in several studies [22-24].

The vegetarian diet is recognized for conferring numerous health benefits such as reduced morbidity and mortality from chronic degenerative diseases [15]. Contrary to the Western perspective of vegetarianism as an adopted lifestyle by choice in adulthood, vegetarianism in India is a way of life from birth for a third of its population. Derived from religious scriptures and beliefs of Hinduism, Jainism, and Buddhism, the practice of vegetarianism goes beyond the principle of ahimsa or nonviolence and is considered a conscious and ethical way of living and eating [25]. Complementary and alternate traditional medical systems such as Ayurveda continue to promote vegetarian practices; a vegetarian diet falls under the domain of biologically based therapies as delineated by the recently named $\mathrm{NCCIH}$ (National Center for Complementary and Integrative Health) [26]. Ayurveda describes food as a means to optimize health and promote well-being by holistically addressing mind, body, behavior, and environment [27]. Hence, the traditional Asian Indian vegetarian diet typically uses grains, dairy products, pulses, legumes, and vegetables. Ayurveda has outlined mind and body-altering attributes of foods [27].

Currently, the practice of vegetarianism by Asian Indians often includes widespread prohibition of beef (out of reverence to the cow). Lacto and lacto-ovo vegetarian practices are common; $1.6 \%$ of the population follows veganism [6]. Therefore, vegetarian practices vary widely with the extent of religious observances and regional preferences from abstaining from all flesh foods, roots, and tubers to including fish alone [25, 27].
The traditional Asian Indian diet has several healthpromoting features. Cereal-legume-pulse combinations are highlights of the cuisine with complementing sources of protein. Native spices such as turmeric, ginger, onion, garlic, chilies, cumin, coriander, and fenugreek provide flavor and aesthetic appeal besides carrying putative medicinal and digestive effects as per Ayurveda [28]. Recent studies endorse some properties as evidenced by the innumerable health benefits of bioactive compounds with potential antioxidant, anti-inflammatory, antimicrobial, antibacterial, and chemopreventive properties [29].

Despite the many touted health-promoting features of the predominantly vegetarian Asian Indian diet, studies report on the increasing rates of NCDs (noncommunicable diseases) such as type 2 diabetes, cardiovascular disease, and metabolic syndrome marked by the raised concentrations of inflammatory markers and cytokines $[13,30]$.

This study aims to explore the relationship between the consumption of a traditional Asian Indian vegetarian diet and the prevalence of diabetes, obesity, and metabolic syndrome among AIs residing in the United States, after controlling for acculturation, dietary and lifestyle habits, family history of diabetes, knowledge of diabetes and CVD risk factors, and demographic characteristics. Data for this study were derived from the first national population-based investigation of AIs in the US. Diabetes among India American (DIA) study included dietary factors, vegetarian status, demographic, acculturation, and clinical risk factors [12].

\section{Methodology}

2.1. Subjects and Data Collection. The sample consisted of 1038 randomly selected Asian Indians, aged 18 years and older, from seven US cities-Houston, TX; Phoenix, AZ; Washington, DC; Boston, MA; San Diego, CA; Edison, NJ; and Parsippany, NJ. The sampling procedure and data collection methodology were reported in prior publications $[12,31]$. Participation was voluntary. Survey data were collected via telephone interviews by trained, multilingual AI staff; the response rate was 37\%. Although the response rate of $37 \%$ is relatively low for an epidemiologic study, it is similar to or higher than the response rate in published health surveys of Asians, Asian Indians, or immigrant ethnic groups $[12,31]$. The possible reasons for a $37 \%$ response rate might be (a) voluntary participation; (b) reluctance to divulge personal information and provide fasting serum blood; (c) not attributing any value to research studies that require time to complete surveys and fasting blood work; (d) ability to understand the purpose and benefits of the study; and (d) barriers associated with confidentiality, trust, and safety. All participants completed blood work (after a 10-hour fast) and anthropometric measurements (height, weight, and waist circumference). Nonparticipants did not differ in gender, educational level, family history, or smoking status, but were significantly older than participants. Blood samples were centrifuged to separate plasma or serum and shipped on ice to three core laboratories for biochemical analysis (Atherotech Laboratory (Birmingham, AL), 
Diabetes Diagnostic Laboratory (Columbia, MO), and Translational Metabolism Unit, Baylor College of Medicine (Houston, TX)). This study was approved by the Institutional Review Board of an academic institution.

\section{Measures}

3.1. Demographic Variables. Information on age in years, gender, marital status (married, never married, and widowed/separated/divorced), level of education (less than high school, high school, some college, college grad, and post $\mathrm{grad} /$ professional), access to conventional health care (health insurance coverage), and self-reported physical health was collected. Income was assessed as a categorical variable with response options from $<\$ 10,000$ to $\geq \$ 150,000$. Body mass index (BMI) was calculated from height and weight $\left(B M I=\mathrm{kg} / \mathrm{m}^{2}\right)$; nativity status (born in US, yes or no) and length of time in the US were also measured. Current health status was self-reported physical health by respondents and recoded as excellent/very good/good (1) and fair/poor (0).

3.2. Acculturation. Acculturation was measured using the nine-question Acculturation Scale for Southeast Asians [32] which assessed two subscales: English proficiency/language and food preferences. Confirmatory factor analysis indicated all items loaded on the subscales and explained $69.3 \%$ of the variance. A higher composite score indicated less acculturation (Cronbach's $\alpha=0.88$ ).

3.3. Dietary and Lifestyle Behavior. Self-reported dietary behavior was calculated from the nutrition subscale (Cronbach's $\alpha=0.78$ ) of the revised Health Promotion Lifestyle, Profile II [33]. A higher dietary behavior score was indicative of a healthier dietary behavior. Diet change after immigration to the United States was also obtained (no $=0$, yes $=1)$. Physical activity was calculated from the exercise subscale ( 9 items that measured the frequency of rigorous or leisure time physical activity; Cronbach's $\alpha=0.83$ ) of the revised Health Promotion Lifestyle, Profile II [33]. The scales ranged from never to routinely with a higher score indicative of physical activity levels. Spirituality status was assessed from the question "do you feel connected with some force greater than yourself?" with response categories "routinely," "often," "sometimes," or "never." Tobacco usage was dichotomized as nonuser (0) or regular/sometime use of one or more of the following: chewing tobacco or beetle leaves (paan), cigarettes, cigars, and smokeless tobacco (1).

3.4. Family History of Diabetes. This was computed from selfreported family history of diabetes. Each occurrence of the chronic condition was rated as $0=$ absent and $1=$ present and summed to obtain a score that ranged from 0 (none) to 7 (siblings, parents, uncles/aunts, and grandparents).

3.5. Fasting Glucose. Fasting capillary glucose $(\mathrm{mg} / \mathrm{dL})$ was measured using Accu-Chek Advantage (Roche Diagnostics, Indianapolis, IN). Although fasting serum glucose was collected and stored, analysis indicated abnormal levels with large standard deviations from the capillary glucose for one-third of the respondents. Hence, fasting capillary glucose was used for calculating cardiometabolic syndrome (CMetS) that has been validated in a prior epidemiological study on Indians in India [34].

3.6. Clinical Factors. Plasma samples were assayed for triglycerides, Lp(a), homocysteine, hsCRP, LDL, and HDL using the vertical auto profile test at the Atherotech Laboratory (Birmingham, AL) as described previously [35].

\section{Definitions}

4.1. Cardiometabolic Syndrome. Cardiometabolic syndrome status was determined according to the International Diabetes Federation (IDF) criteria: presence of central obesity and $\geq 2$ of the following risk factors (RFs): elevated triglycerides $(\geq 150 \mathrm{mg} / \mathrm{dL})$, low HDL $(<40 \mathrm{mg} / \mathrm{dL}$ in males, $<50 \mathrm{mg} / \mathrm{dL}$ in females, or specific treatment for these lipid abnormalities), elevated BP $(\geq 130 / \geq 85 \mathrm{mmHg}$ or treatment of previously diagnosed hypertension), and elevated fasting blood glucose (FBG, $\geq 100 \mathrm{mg} / \mathrm{dL}$ or previously diagnosed type 2 DM) [36]. Central obesity was defined using the genderand ethnicity-specific waist circumference (WC) for Asian Indians [37].

4.2. Diabetes Mellitus (DM). Diabetes was defined as FBG $\geq 126 \mathrm{mg} / \mathrm{dL}$ or a self-report of previously diagnosed DM. Impaired fasting glucose was defined as FBG between 100 and $125 \mathrm{mg} / \mathrm{dL}$.

4.3. Hypertension. Hypertension was defined as $\mathrm{BP} \geq 140$ / $\geq 90 \mathrm{mmHg}$ or a self-report of previously diagnosed hypertension.

4.4. Obesity. Respondents were categorized as normal weight (defined as BMI $<23.0 \mathrm{~kg} / \mathrm{m}^{2}$ ), overweight (BMI between 23 and $\left.25 \mathrm{~kg} / \mathrm{m}^{2}\right)$, and obese $\left(\mathrm{BMI} \geq 25 \mathrm{~kg} / \mathrm{m}^{2}\right)$ based on the Asian criteria [37]. Waist-to-hip ratio was also calculated.

\section{Statistics}

All analyses were done using the Statistical Program for Social Sciences (SPSS) system (version 23.0). Basic descriptive statistics were obtained for demographic, lifestyle, and clinical factors. Logistic regression analysis was used to examine the association between a vegetarian diet and demographic (age, number of years in the US, gender, education, marital status, income, access to health care, self-rated health, English proficiency, and family history of diabetes) and lifestyle factors (dietary habits, body mass index, spirituality, physical activity, and tobacco use). In addition, logistic regression examined the association between a vegetarian diet and prevalence of diabetes, obesity, and metabolic syndrome, controlling for demographic characteristics, lifestyle factors, and clinical factors (lipoprotein(a), high sensitivity C-reactive protein (hsCRP), homocysteine and triglycerides, HDL, and LDL). The acceptance level for statistical significance was $P \leq 0.05$. 


\section{Results}

6.1. Demographic Characteristic and Lifestyle Behavior. The mean age of the subjects was $47.0 \pm 12.8$ years (Table 1 ). A majority of respondents were vegetarians (62.7\%), male (59\%), married (90\%), and had access to health care $(82 \%)$. The modal income was \$75,000-\$100,000; $15 \%$ reported income $<\$ 25,000$. Mean length of residence in the US was $18.5 \pm 11.5$ years, and $1.6 \%$ were born in the US. Fiftyseven percent reported a family history of diabetes, and $6.6 \%$ were current smokers (male predominance).

The mean BMI was $25.4 \pm 3.7 \mathrm{~kg} / \mathrm{m}^{2}$. Using the Asian criteria [37], 25\% were overweight (BMI between 23 and $\left.25 \mathrm{~kg} / \mathrm{m}^{2}\right)$ and $49.8 \%$ were obese $\left(\mathrm{BMI} \geq 25 \mathrm{~kg} / \mathrm{m}^{2}\right)$. However, using the standard criteria by the National Institute of Diabetes and Digestive and Kidney Diseases, 38\% were overweight (BMI between 25 and $30 \mathrm{~kg} / \mathrm{m}^{2}$ ) and $11 \%$ were obese $\left(\mathrm{BMI} \geq 30 \mathrm{~kg} / \mathrm{m}^{2}\right)$. More than $50 \%$ failed to follow the USDA Food Pyramid recommendations for fruit and vegetable consumption (https://www.cnpp.usda.gov/mypyramid), and $65 \%$ did not follow the US Surgeon General's recommendation for physical activity ( 30 minutes a day at least 5 times a week).

The prevalence of chronic diseases was high; rate of diabetes was $17.4 \%$, prediabetes was $33 \%$, metabolic syndrome was $38.2 \%$, and $48 \%$ were obese.

\section{Vegetarian Dietary Habits by Selected Respondent Characteristics}

Approximately two-thirds (62\%) of AIs reported that they consumed a vegetarian diet, and 50\% indicated that their diet has changed after immigrating to the United States. Multivariate logistic regression was performed to examine the association between a vegetarian diet and demographic and lifestyle factors (Table 2). A vegetarian lifestyle was associated with respondents who are less acculturated, not proficient in English, and who reported that their diet had not changed after coming to the US. Asian Indians who self-rated their health status to be fair/poor and were readers of the food label consumed a vegetarian diet. Females were more likely to report a vegetarian diet. Furthermore, respondents with lower education level and who did not consume tobacco in any form reported a vegetarian dietary habit (approaching significance: $P<0.10$; Table 2).

Demographic variables were significantly associated with a chronic disease risk as expected (not shown in the table). For example, age was positively associated with both risk for diabetes and metabolic syndrome showing chronic disease increased with age; with each year of increase in age, the risk for diabetes increased by $5 \% \quad(\mathrm{OR}=1.05 ; 95 \%$ $\mathrm{CI}=1.02,1.08)$ and metabolic syndrome by $3 \%(\mathrm{OR}=1.03$; $95 \% \mathrm{CI}=1.01,1.05)$. Participants with higher incomes also had a higher risk for diabetes $(\mathrm{OR}=1.87 ; 95 \% \mathrm{CI}=1.06$, 3.55) than those with a lower income. Family history of diabetes had a strong association with the risk for diabetes $(\mathrm{OR}=3.03 ; 95 \% \mathrm{CI}=1.69,5.42)$, metabolic syndrome $(\mathrm{OR}=1.19 ; 95 \% \mathrm{CI}=0.97,1.45)$, and obesity $(\mathrm{OR}=1.53$; $95 \% \mathrm{CI}=0.94,2.51)$. Lack of a healthier dietary behavior (as indicated by a lower intake of fruits and vegetables, grains,
TABle 1: Demographic characteristics of participants [51].

\begin{tabular}{|c|c|c|}
\hline Variables & Frequency & Percent \\
\hline \multicolumn{3}{|l|}{ Sex } \\
\hline Male & 609 & $58.7 \%$ \\
\hline Female & 429 & $41.3 \%$ \\
\hline Age & $47.0 \pm 12.8$ years & \\
\hline \multicolumn{3}{|l|}{ Annual household income } \\
\hline$<\$ 25,000$ & 108 & $14.7 \%$ \\
\hline$\$ 25,000-\$ 74,999$ & 236 & $32.0 \%$ \\
\hline$\$ 75,000-\$ 99,999$ & 248 & $33.6 \%$ \\
\hline$\geq \$ 100,000+$ & 145 & $19.7 \%$ \\
\hline \multicolumn{3}{|l|}{ Education } \\
\hline$\leq$ High school grad & 92 & $10.5 \%$ \\
\hline College grad or higher & 785 & $89.5 \%$ \\
\hline \multicolumn{3}{|l|}{ Have health insurance } \\
\hline No & 150 & $18.4 \%$ \\
\hline Yes & 666 & $81.6 \%$ \\
\hline \multicolumn{3}{|l|}{ Marital status } \\
\hline Currently married & 804 & $90.2 \%$ \\
\hline Formerly married/never married & 87 & $9.8 \%$ \\
\hline Body mass index & $25.2 \pm 4.2 \mathrm{~kg} / \mathrm{m}^{2}$ & \\
\hline \multicolumn{3}{|l|}{ English proficiency } \\
\hline Very well/pretty well & 793 & $88.3 \%$ \\
\hline Not too well/not at all & 105 & $11.7 \%$ \\
\hline Years lived in the US & $18.5 \pm 11.5$ years & \\
\hline$<10$ years & 252 & $30.6 \%$ \\
\hline$\geq 10$ years & 572 & $69.4 \%$ \\
\hline \multicolumn{3}{|l|}{ Tobacco use } \\
\hline Never & 824 & $92.0 \%$ \\
\hline Sometimes/regular user & 72 & $8.0 \%$ \\
\hline \multicolumn{3}{|l|}{ Self-rated health } \\
\hline Good/excellent & 745 & $84.8 \%$ \\
\hline Fair/poor & 134 & $15.2 \%$ \\
\hline \multicolumn{3}{|l|}{ Vegetarian } \\
\hline Yes & 553 & $62.7 \%$ \\
\hline No & 329 & $31.7 \%$ \\
\hline \multicolumn{3}{|l|}{ Diet changed in the US } \\
\hline Yes & 432 & $51.1 \%$ \\
\hline No & 413 & $48.9 \%$ \\
\hline
\end{tabular}

Tobacco users are respondents who indicated regular or sometimes usage of cigarettes, bidis, chewing tobacco (paan or beetle leaves), smokeless tobacco, and cigars. Spirituality is a subscale of the health promotion lifestyle profile scale (summation of 9 items). Physical activity is a subscale of the health promotion lifestyle profile scale (summation of 9 items). Proficiency in English is assessed by respondents who indicated that they can speak English very well or pretty well. Current health status was assessed by selfreported physical health by respondents. Percentages are valid percentages. Demographic characteristics of the participants have been presented in earlier studies [51].

protein, and nuts and higher intake of fat) omitting breakfast and not reading food labels showed an increased risk for diabetes while the consumption of fruits and vegetables reduced 
TABLE 2: Association of vegetarian diet to demographic and lifestyle characteristics.

\begin{tabular}{|c|c|c|c|c|c|}
\hline \multirow{2}{*}{ Variables } & \multirow{2}{*}{ Variables } & \multicolumn{2}{|c|}{ Vegetarian diet } & \multirow{2}{*}{$\begin{array}{c}\text { Adjusted odds ratio } \\
(95 \% \mathrm{CI})\end{array}$} & \multirow{2}{*}{$P$ value } \\
\hline & & Yes & No & & \\
\hline \multirow{2}{*}{ Gender } & Male & $296(56.4 \%)$ & $229(43.6 \%)$ & \multirow{2}{*}{$0.42(0.25,0.70)$} & \multirow{2}{*}{0.001} \\
\hline & Female & $257(72.0 \%)$ & $100(28.0 \%)$ & & \\
\hline \multirow{2}{*}{ Age } & $<50$ years & $270(60.8 \%)$ & $174(39.2 \%)$ & \multirow{2}{*}{$0.94(0.56,1.59)$} & \multirow{2}{*}{0.822} \\
\hline & $\geq 50$ years & $278(65.1 \%)$ & $149(34.9 \%)$ & & \\
\hline \multirow{2}{*}{ Access to care } & No & $110(77.5 \%)$ & $32(22.5 \%)$ & \multirow{2}{*}{$1.36(0.69,2.76)$} & \multirow{2}{*}{0.369} \\
\hline & Yes & $393(60.0 \%)$ & $262(40.0 \%)$ & & \\
\hline \multirow{2}{*}{ Years lived in the US } & $<10$ years & $157(63.1 \%)$ & $92(36.9 \%)$ & \multirow{2}{*}{$1.02(0.99,1.04)$} & \multirow{2}{*}{0.211} \\
\hline & $\geq 10$ years & $350(62.1 \%)$ & $214(37.9 \%)$ & & \\
\hline \multirow{2}{*}{ Education } & $<$ high school & $73(81.1 \%)$ & $17(18.9 \%)$ & \multirow{2}{*}{$0.42(0.15,1.15)$} & \multirow{2}{*}{0.091} \\
\hline & College degree or higher & $467(60.5 \%)$ & $305(39.5 \%)$ & & \\
\hline \multirow{2}{*}{ Marital status } & Not currently married & $47(55.3 \%)$ & $38(44.7 \%)$ & \multirow{2}{*}{$1.57(0.72,3.44)$} & \multirow{2}{*}{0.255} \\
\hline & Currently married & $501(63.3 \%)$ & $290(36.7 \%)$ & & \\
\hline \multirow{2}{*}{ Physical activity $^{\dagger}$} & Sedentary & $182(65.7 \%)$ & $95(34.3 \%)$ & \multirow{2}{*}{$0.80(0.53,1.21)$} & 031 \\
\hline & Active & $355(60.5 \%)$ & $232(39.5 \%)$ & & 0.31 \\
\hline & No & $44(88.0 \%)$ & $6(12.0 \%)$ & & 078 \\
\hline Spiritual* & Yes & $499(52.6 \%)$ & $322(47.4 \%)$ & $0.95(0.64,1.39)$ & 0.78 \\
\hline Feel connected with some force & Less spiritual & $175(32.2 \%)$ & $122(37.2 \%)$ & & \\
\hline greater than yourself? & Spiritual & $368(67.8 \%)$ & $206(62.8 \%)$ & $0.68(0.43,1.06)$ & 0.090 \\
\hline & Not very well & $86(87.8 \%)$ & $12(12.2 \%)$ & & \\
\hline English proficiency & Well/pretty well & $460(59.4 \%)$ & $315(40.0 \%)$ & $2.50(0.74,8.41)$ & 0.141 \\
\hline & Fair/poor & $69(53.5 \%)$ & $60(46.5 \%)$ & & \\
\hline Selt-rated health ${ }^{39}$ & Good-excellent & $465(63.7 \%)$ & $265(36.3 \%)$ & $2.01(1.11,3.62)$ & 0.021 \\
\hline Income & $<\$ 100,000$ & $313(65.2 \%)$ & $167(34.8 \%)$ & & \\
\hline Income & $\geq \$ 100,000$ & $129(52.7 \%)$ & $116(47.3 \%)$ & $1.18(0.76,1.86)$ & 0.463 \\
\hline & Never & $511(63.8 \%)$ & $290(36.2 \%)$ & & \\
\hline Tobacco use $\mathrm{e}^{\mathrm{yy}}$ & Sometimes/always & $32(47.1 \%)$ & $36(52.9 \%)$ & $2.11(0.91,4.88)$ & 0.082 \\
\hline & No & $294(62.7 \%)$ & $112(37.3 \%)$ & & \\
\hline Diet changed in the US & Yes & $224(61.6 \%)$ & $202(38.4 \%)$ & $0.49(0.32,0.77)$ & 0.002 \\
\hline & Never/sometimes & $48(58.5 \%)$ & $34(41.5 \%)$ & & \\
\hline Healthy dietary habits (total) & Often/always & $490(62.6 \%)$ & $293(37.4 \%)$ & $1.69(0.58,4.90)$ & 0.338 \\
\hline Choose diet low in fat \& saturated fat & Never/sometimes & $301(60.0 \%)$ & $201(40.0 \%)$ & & 0.869 \\
\hline Choose diet low in fat $\&$ saturated fat & Often/always & $176(66.7 \%)$ & $88(33.3 \%)$ & $0.98(0.73,1.31)$ & 0.869 \\
\hline Limit use of sugar & Never/sometimes & $320(62.6 \%)$ & $195(37.4 \%)$ & & 0627 \\
\hline Limit use of sugar & Often/always & $155(65.7 \%)$ & $81(34.3 \%)$ & $1.04(0.89,1.21)$ & 0.627 \\
\hline Consume $3-5$ servinos of yeotables ner day & Never/sometimes & $242(57.6 \%)$ & $178(42.4 \%)$ & 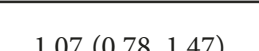 & 0662 \\
\hline Consume $3-5$ servings of vegetables per day & Often/always & $272(67.3 \%)$ & $132(32.7 \%)$ & $1.07(0.78,1.47)$ & 0.662 \\
\hline Consume 2-4 servinos of fruits ner & Never/sometimes & $308(61.5 \%)$ & $193(38.5 \%)$ & 10) & 0.197 \\
\hline Consume $2-4$ servings of fruits per day & Often/always & $185(64.2 \%)$ & $103(35.8 \%)$ & $0.83(0.62,1.10)$ & 0.197 \\
\hline Read food labels & Never/sometimes & $241(57.9 \%)$ & $175(42.1 \%)$ & $137(107,175)$ & 0011 \\
\hline Kead rood labels & Often/always & $216(69.0 \%)$ & 97 (31.0\%) & & \\
\hline
\end{tabular}

${ }^{\dagger}$ Physical activity is a subscale of the health promotion lifestyle profile scale (summation of 9 items; range 0 (never) to 3 (always), higher scores indicate a more physically active lifestyle reported by respondents); ${ }^{*}$ Spirituality is a subscale of the health promotion lifestyle profile scale (summation of 9 items; range 0 (never) to 3 (always), higher scores indicate higher levels of spirituality reported by respondents). Respondents were categorized "physically active" if they responded often or routinely and "physically not active" if responses were never or sometimes. Similarly, respondents were grouped as spiritual if they responded often or routinely for the nine questions and "not spiritual" if responses were never or sometimes; ${ }^{\dagger \dagger}$ Proficiency in English is assessed by respondents who indicated that they can speak English very well or pretty well $(1)$ or not very well/not at all $(0) .{ }^{*}$ Income was recoded to $<\$ 100,000(0)$ and $\geq \$ 100,000$ (1). ${ }^{\$ \varsigma}$ Tobacco users are respondents who indicated regular or sometimes usage of cigarettes, chewing tobacco (paan or beetle leaves), smokeless tobacco, and cigars (1) and nonusers $(0) .{ }^{99}$ Current health status was self-reported physical health by respondents and recoded as excellent/very good/good (1) and fair/poor (0). Access to care indicates having health insurance (private, Medicaid, and Medicare) (1) or no health insurance (0). $P$ value is based on logistic regression analysis. Demographic characteristics of the participants have been presented in earlier studies [51]. 
the risk. High levels of HDL or the good cholesterol reduced the risk for diabetes.

\section{Are Vegetarians at Lower Risk for Chronic Diseases?}

Binary logistic regression was performed to assess the association between a vegetarian diet (primary independent variable) and the prevalence of diabetes, metabolic syndrome, and obesity as the dependent variables, controlling for demographic characteristics, lifestyle factors, and clinical factors (lipoprotein(a), hsCRP, homocysteine, triglycerides, HDL, and LDL) in the model. Multivariate-adjusted odds ratios (OR) are shown in Table 3. As shown in the adjusted model, overall, vegetarian status reduced the risk of diabetes by $44 \%(\mathrm{OR}=0.55 ; 95 \% \mathrm{CI}=0.31,0.99)$. However, AIs who consumed a vegetarian diet did not have a reduced risk for metabolic syndrome and obesity $(P>0.05)$.

\section{Discussion}

To the best of our knowledge, this is the first study that explored the metabolic advantages of a vegetarian diet among AIs residing in the United States, after controlling for known confounders such as lifestyle factors, acculturation levels, demographic characteristics, and family history of diabetes. A large percentage (62\%) of the sample reported maintaining the traditional practice of consuming a vegetarian diet. A vegetarian diet in this study was described as a lacto-vegetarian diet without eggs, meat, fish, and poultry with a few exceptions that omitted dairy. Our findings confirm that vegetarian status was a protective factor and lowered the risk for diabetes, but not for obesity or metabolic syndrome. Specific dietary macronutrients and micronutrients associated with metabolic benefits in the prevention and treatment of diabetes were not assessed.

Although research has pointed out the higher tendency for AIs in general towards developing type 2 diabetes with a higher risk than the overall US population [17, 21, 23], recent comparisons of urban Indians with their US immigrant counterparts [24] showed a lower prevalence of type 2 diabetes among AI immigrants with a higher prevalence of prediabetes. The results corroborate with these findings. Prevalence of prediabetics in the sample was also high, and while incidence of prediabetes is unknown in this ethnic group, it is very likely that $\mathrm{AI}$ immigrants with a prediabetes diagnosis who are physically active and have adopted lifestyle and vegetarian and/or plant-based dietary practices may decrease their dietary risk for progression to diabetes. An increased awareness and knowledge of these health consequences may prompt migrant AIs to make prudent dietary and health-promoting lifestyle food [38] as well as programmed physical activity changes; all of which can contribute to a decreased risk. This is encouraging and needs to be reinforced through public health and nutrition interventions targeted towards Asian Indians.

\section{Metabolic Syndrome and Obesity}

Our study results showed that the vegetarian diet was not protective against metabolic syndrome and obesity. One plausible explanation might point to limitations such as risks like body composition and the nutritional quality of the vegetarian diet consumed that were not assessed in this study. These egregious factors seem to earmark this group towards increased vulnerability to metabolic disease, that is, the unique body composition marked by increasing abdominal obesity and dietary lifestyle practices. The typical AI phenotype has a higher body fat, higher truncal, subcutaneous, and intra-abdominal fat with less lean body mass [20], a feature that is also noted in AI neonates [19]. This coupled with biochemical indicators such as high levels of inflammatory markers, low levels of adiponectin, the coexistence of hyperinsulinemia, insulin resistance, hypertriglyceridemia, abnormal lipid profiles, endothelial dysfunction, and hyperhomocystenemia sets the stage for chronic low-grade inflammation that exacerbates morbidity and mortality. Since muscle mass is an indicator of insulin sensitivity, a lower muscle mass reroutes energy from large carbohydrate meals typical in the Asian Indian diet into hepatic lipogenesis compromising muscle glycogen synthesis. The outcome is atherogenic dyslipidemia [21], a menacing combination that is metabolically linked to insulin resistance, promotes subclinical chronic inflammation, and is strongly associated with type 2 diabetes and cardiovascular disease. Underlying genetic factors such as gene variants and polymorphisms further exacerbate the situation. For example, the ectonucleotide pyrophosphate phosphodiesterase 1 (ENPP1) 121Q variant is implicated in negatively influencing insulin receptor signaling [39] along with the DOK5 gene [40] that increases the risk in both natives in India as well as migrant Asian Indians [39]. Other genetic associations related to chronic diseases noted in this population include the apolipoprotein E gene polymorphisms, the myostatin gene in abdominal obesity and obesity [41], the AMDI variant in homocysteine metabolism that predisposes children to obesity [42], and the PPAR-gamma polymorphisms contributing to nonalcoholic fatty liver disease [43].

Another risk factor is the elevated levels of homocysteine in Asian Indians resulting from a widespread deficiency of vitamin B12 consequent to following a vegetarian diet [44]. High homocysteine levels are implicated as an independent risk factor for cardiovascular disease with deleterious effects primarily affecting the chronic disease process through the oxidative stress [45], modifying protein functionality [46] and subsequent gene expression through altered methylation profiles [47]. Deficiencies and/or altered functioning of the MTHFR (methylenetetrahydrofolate reductase) enzyme is a known mechanism in the elevation of homocysteine levels in the folate vitamin B12 metabolic pathway. Two common gene variants (C677T and A1298C) have been implicated as contributing to defects in the MTHFR gene resulting in metabolic aberrations. A study on the effect of these polymorphisms in more than 400 individuals from different ethnic populations in India based on linguistic lineage and geographic location identified the predominance of the 


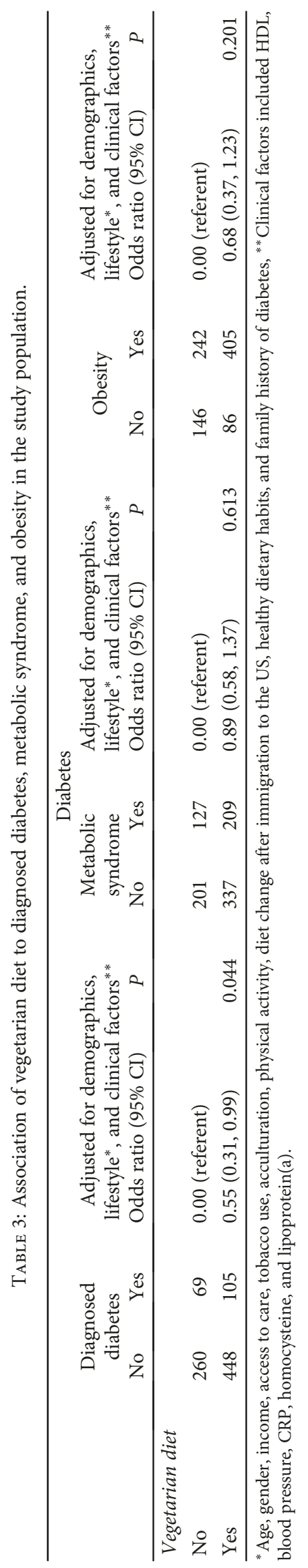


A1298C polymorphism making it a factor that needs further investigation in the quest to identify contributors to the chronic disease paradigm [48]. An examination of the association between homocysteine levels and the C667 T and A1298C polymorphisms in hypertensive patients showed that the presence of either allele C677 T/1298 CC genotypes increased the risk of hypertension. Patients with the MTHFR 1298CC genotype had significantly higher homocysteine levels compared to those with the 1298AA genotype $[49,50]$.

The dramatic increase of chronic diseases like type 2 diabetes mellitus and cardiovascular disease among Asian Indians seems surprising as there is a long-standing tradition of following a vegetarian diet in this population; a vegetarian plant-based diet has been shown to have lower calories, lower saturated fat content, higher fiber, and similar healthpromoting features [51]. Researchers like Dr. Ornish, who have reported success in reversing heart disease, have arguably based the main thrust of success on plant-based vegetarian or vegan diets $[52,53]$. This suggests that a comparative study between the Asian Indian vegetarian diet and the vegetarian diet followed by the Seventh Day Adventists in the US could yield vital information on the health effects of the types of vegetarian diets as the latter group has been found to have pronounced benefits [54].

Hence, a few questions arise about the Asian Indian diet such as do they consume an unhealthy vegetarian diet? Or, what is the profile of the current AI vegetarian diet? Singh et al. [15] in a recent review describe certain features of the modern day AI vegetarian diet impacted by a nutrition transition [16]. They highlight the key negative changes as (a) the substitution of refined grains, for example, white rice for whole grains such as brown rice; (b) an emphasis and overconsumption of refined carbohydrates particularly potatoes at the expense of other whole plant foods such as lentils, vegetables, fruits, nuts and seeds, and whole unrefined grains; (c) the increased use of omega-6-rich hydrogenated vegetable oils, palm oil and safflower oil instead of monounsaturated and omega-3-rich olive oil, groundnut oil, rice bran oil, and mustard oil; and (d) the increased consumption of fried/ fast/processed foods. This so called "contaminated vegetarianism" $[27,55]$ profile results from a general lack of awareness of the beneficial qualities of traditional components, a desire to follow Westernized dietary practices as well as the lack of knowledge on modifying traditional diets by altering specific ingredients or replacing cooking methods. On a more positive note, studies on Canadian AI immigrants report a variety of health-promoting behaviors such as an increased consumption of fruits and vegetables as well as increased use of grilling over frying in food preparation [38]. Our study participants who were vegetarian did report a higher vegetable consumption $(67.3 \%)$. This is a positive behavior that needs to be encouraged. This underscores the importance of making culturally sensitive recommendations to alter negative behaviors while reinforcing/encouraging positive ones to improve health outcomes. Over the past four decades, the practice of vegetarianism among Asian Indians appears to have had fewer followers, both in the older and the younger generations, in the US and among natives in India.
Our results indicated that a vegetarian diet was associated with respondents who were less acculturated and less educated, not proficient in English, and primarily females who also avidly read food labels. Studies on the dietary acculturation of AI immigrants in 1976 and 1986 reported on altered vegetarian status as one of the hallmarks of becoming acculturated $[56,57]$. A third of the vegetarians became nonvegetarians within a window period of two months to a year and were eating beef if a person was so inclined by seven years of residing in the US. Females acculturate slower than males; perhaps, as gatekeepers of food and tradition, they hold a higher allegiance to traditional vegetarian dietary practices. Their concern for nonvegetarian ingredients in vegetarian foods may have also prompted greater label reading as was evident in their label use.

The present study did not examine the food components of the diet consumed. Previous dietary acculturation studies reported that altered vegetarian practices in AI immigrants $[56,57]$ included a change in consumption of ghee, yogurt, Indian bread, rice dishes, and tea from frequent to low moderate upon migration with a concomitant increase in fruit juice, cheese, American breads, dry cereal, soft drinks, and coffee. A study conducted in New York City and Washington in 1999 indicated that vegetarian food patterns and food choices of migrant Asian Indians undergo substantial changes with increasing residence in the US [58]. While consumption of white bread, roots and tubers, vegetable oils, legumes, and tea changed a little, the consumption of fruit juice, chips, fruits, margarine, cola, and alcoholic beverages increased. It is not surprising that when new foods or ingredients are incorporated or substituted for native foods convenience and cost are overarching factors often resulting in calorie dense choices. A lack of nutrition knowledge, inability to judge appropriate portion sizes, being unaware that vegetarian foods can be unhealthy and have large quantities of salt, sugar, and "invisible fats" such as oils, butter, and ghee, increasing the frequency of consumption of "festival/foods eaten on special occasions" that may be calorie dense and fat laden [59], and an easy access to convenient, prepared, frozen native vegetarian entrees in Asian Indian retail outlets are factors fostering these acculturative dietary practices. Participants in a community-based participatory focus group on psychosocial and cultural perceptions had made assumptions that vegetarian diets were low fat or healthy and expressed disbelief that vegetarians could suffer from heart disease [60].

Data on dietary habits of immigrant Asian Indians is limited and is based on small samples in different geographic locations in the US $[58,61-64]$ but has been useful in providing information on dietary trends in the population. A highfat intake (32\% in migrant AIs), a high omega-6 to omega-3 ratio, the continued use of trans fats as a cooking medium [21], and increased consumption of large carbohydrate meals primarily made up of refined, processed grains with a low fiber content are noted as dietary changes. Our results showed that an unhealthy dietary behavior such as a lower intake of fruits and vegetables, grains, protein, and nuts and higher intake of fat increased the risk for diabetes. While the participants were educated, $43 \%$ indicated that they do 
not read food labels and one-third had a sedentary lifestyle that are likely to have an overriding influence on the metabolic profile and chronic disease progression in $\mathrm{AI}$ immigrants. A recent examination of the association between vegetarian dietary patterns and obesity/overweight in a 239 AI member cohort of the Adventist health study showed the potential of whole plant foods, for example, nuts in preventing obesity [15].

Given the alarming increase in NCDs, especially at a younger age, the need for longitudinal population-based epidemiological risk factors for chronic inflammatory conditions such as metabolic syndrome, cardiovascular disease, and diabetes across the life span is underscored. Our results are of great concern for this ethnic population experiencing acculturation and/or assimilation in the US as these diseases are occurring at an early age leading to premature morbidity and mortality $[65,66]$. The results also underscore the importance of increasing awareness and educating Asian Indians on the importance of (a) maintaining the authenticity of the traditional Asian Indian vegetarian diet, (b) being mindful of refined processed products, sources and types of fat, and undesirable food preparation and consumption practices, (c) encouraging consumption of whole, unprocessed foods, (d) maintaining physically active lifestyles, and (e) incorporating stress management. Healthcare professionals working with Asian Indian communities should ensure that these messages are targeted across the life span stages so that healthy patterns can be established at an early age. It is equally important to not make assumptions that all vegetarian and/or plant-based diets are healthy diets.

There are currently a few studies among Indians residing in India $[6,67,68]$ which highlight macronutrient and micronutrient imbalances in their dietary practices. A large cross-sectional study $(n=156,317$ adults in the 20-49 age group) from the National Family Health Survey- 3 conducted between 2005 and 2006 showed that lacto-vegetarian, lactoovo vegetarian, and semivegetarian diets were associated with lower prospects $(\sim 30 \%)$ of developing diabetes than pesco-vegetarian and nonvegetarian diets regardless of BMI [6]. Further, men on a lacto-vegetarian and semivegetarian diets had a significantly lower odds ratio of diabetes risk compared to women for whom the consumption of a lactovegetarian diet was protective. Studies on migrant Japanese have confirmed that succeeding generations maintain the intake of foods that are a mark of their cultural identity but often incorporate or substitute accessory high calorie dense foods $[69,70]$. For example, second-generation Japanese Americans had higher animal-protein and animal-fat intakes with a diet that resembled more the diet of US than that of Japan [71]. If similar changes and trends are projected among Asian Indians, it could have several ramifications-that the healthful nature of a plant-based diet could become unhealthy with the decreased use of plant foods and the increased reliance on prepared highly refined sugar/cereal and fat foods. The use of stress-released mechanisms such as yoga and meditation has been shown to help in preventing or mitigating cardiovascular diseases [72] prevalent in this ethnic group. The rate of cardiovascular disease in this ethnic group has been estimated to be three times higher than that in Whites [73]. Hence, future studies can examine if Asian Indian vegetarians have the same insulin sensitivity as other ethnic groups who have adopted vegetarian diets. Furthermore, this new immigrant group, despite having some "health-promoting" beliefs such as a predominantly plantbased diet, has shown increased vulnerability towards chronic lifestyle diseases-the Asian Indian Paradox $[51,73]$. Hence, additional questions can assess if corrupting dietary factors such as high use of fried foods, refined grains, and sugars and a decreased use of vegetables and whole grains increase their risk despite the "plant-based" features of their cuisine. Today, chronic diseases are taking up a large percentage of health costs, and any information that will help to understand the etiology of chronic diseases can be helpful in their prevention.

A study by Tonstad et al. [74] clearly showed that all variants of vegetarian diets (vegan, lacto-ovo, and pescovegetarian and semivegetarian) were associated with substantially lower risk of type 2 diabetes and lower BMI than nonvegetarian diets, and the protection afforded by vegan and lacto-ovo vegetarian diets was the strongest. Why then is this ethnic group ( $62 \%$ of whom were vegetarians) showing increased vulnerability towards metabolic abnormalities?

\section{Study Limitations}

Results of the current study should be considered in context to the following limitations. Vegetarian status, state of diabetes, and lifestyle factors were self-reported and may include social desirability bias that underestimate healthy lifestyle behaviors. Furthermore, the simplistic grouping of a vegetarian and nonvegetarian diets does not capture the variants of the Asian Indian vegetarian diets (vegan, lactoovo, and pesco-vegetarian and semivegetarian) to provide a better understanding of the association between a vegetarian diet and risk for NCDs. The present cross-sectional study described a lacto-vegetarian diet without eggs, meat, fish, and poultry with a few exceptions that omitted dairy; the individual components of the diet were not examined. While the study results pointed to the higher prevalence of prediabetes within the population, the actual incidence of diabetes was low. Perhaps, an examination of individual food components under the broad umbrella of a "lactovegetarian diet" from a longitudinal perspective may have provided more insight into the role of dietary components in influencing metabolic markers. Future studies should explore the duration and type of vegetarian practice on the incidence of diabetes. Recent explorations of over 800 South Asians in the MASALA study have explored this relationship between the types of vegetarian patterns and metabolic and anthropometric markers [9]. Similar explorations of dietary practices across India [22] point to the role of food choices within a dietary pattern that can make or mar the integrity of the vegetarian practice.

We agree that using capillary blood glucose measurement (rather than serum glucose) is a limitation of this study, and the true prevalence rates might be slightly lower. However, the prevalence of diabetes was high (17.4\%) and there was a strong correlation between the average capillary blood 
glucose levels and HbA1c $(r=0.77)$. Prior studies have also highlighted the reluctance of the Asian Indian participants to give blood for interventional studies. For example, Dr. Chow used to measure blood sugar with a finger stick [34].

Risk for diabetes, obesity, and metabolic syndrome is associated with many factors such as total calorie intake, amount of fat consumption, and amount of meat and vegetable consumption that might modify the risk of NCDs. However, the current study adds to the body of literature as results combine behavioral, anthropometric, and clinical data to present unique perspectives on AIs from a large national study; currently, no national dataset exists for this high-risk (immigrant) ethnic group in the US. While a closer look at macronutrient and micronutrient consumption (e.g., total calorie intake, amount of fat consumption, amount of meat, and vegetables) in AIs can provide a better understanding of excess/deficiencies in AIs, a comprehensive dietary analysis is challenging for Asians in general due to limited ethnic (Asian) food items in currently available nutrition software. Hence, the only way to calculate this will be to enter the ingredient list for each item. Further additional challenges to this process are variations in traditional Indian diet from different geographical regions (e.g., East, West, North, and South). For example, "roti" or Indian bread could be prepared in different ways and calories, fat, and carbohydrate will vary based on the type of roti and its ingredients. Under the circumstances, self-reported dietary behavior of participants, using a reliable and valid nutrition subscale from the revised Health Promotion Lifestyle, Profile II, was considered robust to assess the dietary behavior and diet change for AIs and was used in the current study. Dietary behaviors (consumption of fat, sugar, servings of vegetables, fruits, and carbohydrates and reading food labels) were included in the multivariate regression model, but none attained significance in the model. Evidence from the recent literature suggest that self-reported dietary behavior is associated with a myriad of chronic diseases and outcomes among various racial/ ethnic minority groups and even among select groups of non-Hispanic Whites. More specifically, health outcomes associated with dietary behavior have varied widely from hypertension/blood pressure, diabetes, CVD excess weight/ obesity, and other health issues [75-88].

\section{Conclusion}

The findings clearly indicated that while a vegetarian diet lowered the risk for diabetes among immigrant AIs in the United States, paradoxically, immigrant AIs have high rates of diabetes, metabolic syndrome, and obesity. A vegetarian lifestyle was associated with females, food label users, respondents with poor/fair current health status, and those who were less acculturated and reported that their diet had not changed after coming to the US. Hence, there exists a gap between knowledge of NCD risk factors and the need for screenings and lifestyle modifications to effectively lower those risks. Plans for future research include enhancing data collection to include the variants of vegetarian diets and the quality of vegetarian diets followed by this ethnic group that negatively impacts body composition and subsequent NCDs to better understand the associations in this high-risk ethnic group using similar population-based studies.

\section{Conflicts of Interest}

The authors declare that they have no conflicts of interest.

\section{Acknowledgments}

This project was funded by the American Association of Physicians of Indian Origin (AAPI) grant.

\section{References}

[1] New America Media, "Census: Asian-Indian population explodes across U.S.," 2012, May 2012 http://newamerica media.org/2011/05/census-asian-indian-population-explodesacross-us.php.

[2] R. Venkataraman, N. C. Nanda, G. Baweja, N. Parikh, and V. Bhatia, "Prevalence of diabetes mellitus and related conditions in Asian Indians living in the United States," The American Journal of Cardiology, vol. 94, no. 7, pp. 977980, 2004.

[3] A. M. Kanaya, C. L. Wassel, D. Mathur et al., "Prevalence and correlates of diabetes in South Asian Indians in the United States: findings from the metabolic syndrome and atherosclerosis in South Asians living in America study and the multi-ethnic study of atherosclerosis," Metabolic Syndrome and Related Disorders, vol. 8, no. 2, pp. 157-164, 2010.

[4] E. A. Enas, V. Mohan, M. Deepa, S. Farooq, S. Pazhoor, and H. Chennikkara, "The metabolic syndrome and dyslipidemia among Asian Indians: a population with high rates of diabetes and premature coronary artery disease," Journal of the Cardiometabolic Syndrome, vol. 2, no. 4, pp. 267-275, 2007.

[5] M. Dinu, R. Abbate, G. F. Gensini, A. Casini, and F. Sofi, "Vegetarian, vegan diets and multiple health outcomes: a systematic review with meta-analysis of observational studies," Critical Reviews in Food Science and Nutrition, vol. 57, no. 17, pp. 3640-3649, 2016.

[6] S. Agrawal, C. J. Millett, P. K. Dhillon, S. V. Subramanian, and S. Ebrahim, "Type of vegetarian diet, obesity and diabetes in adult Indian population," Nutrition Journal, vol. 13, no. 1, p. 89, 2014.

[7] K. Shridhar, P. K. Dhillon, L. Bowen et al., "Nutritional profile of Indian vegetarian diets - the Indian Migration Study (IMS)," Nutrition Journal, vol. 13, no. 1, p. 55, 2014.

[8] R. Gupta, Predictors of Health among Indians in United States, India Association of North Texas, Dallas, TX, USA, 2004.

[9] M. D. Gadgil, C. A. M. Anderson, N. R. Kandula, and A. M. Kanaya, "Dietary patterns in Asian Indians in the United States: an analysis of the metabolic syndrome and atherosclerosis in South Asians living in America study," Journal of the Academy of Nutrition and Dietetics, vol. 114, no. 2, pp. 238 243, 2014.

[10] P. Rangaswamy, "Asian Indians in Chicago: growth and change in a model minority," in Ethnic Chicago: A Multicultural Perspective, Eerdmans publishing Company, Chicago, IL, USA, 1996.

[11] A. Mukherjea, K. C. Underwood, A. L. Stewart, S. L. Ivey, and A. M. Kanaya, "Asian Indian views on diet and health in the United States: importance of understanding cultural and social 
factors to address disparities," Family \& Community Health, vol. 36, no. 4, pp. 311-323, 2013.

[12] R. Misra, T. Patel, P. Kotha et al., "Prevalence of diabetes, metabolic syndrome, and cardiovascular risk factors in US Asian Indians: results from a national study," Journal of Diabetes and its Complications, vol. 24, no. 3, pp. 145-153, 2010.

[13] S. A. Mohanty, S. Woolhandler, D. U. Himmelstein, and D. H. Bor, "Diabetes and cardiovascular disease among Asian Indians in the United States," Journal of General Internal Medicine, vol. 20, no. 5, pp. 474-478, 2005.

[14] A. Raji and J. Plutzky, "Insulin resistance, diabetes, and atherosclerosis: thiazolidinediones as therapeutic interventions," Current Cardiology Reports, vol. 4, no. 6, pp. 514521, 2002.

[15] P. N. Singh, K. N. Arthur, M. J. Orlich et al., "Global epidemiology of obesity, vegetarian dietary patterns, and noncommunicable disease in Asian Indians," The American Journal of Clinical Nutrition, vol. 100, Supplement 1, pp. 359S-364S, 2014.

[16] G. Rayner, C. Hawkes, T. Lang, and W. Bello, "Trade liberalization and the diet transition: a public health response," Health Promotion International, vol. 21, Supplement 1, pp. 67-74, 2006.

[17] M. D. Gadgil, C. A. Anderson, N. R. Kandula, and A. M. Kanaya, "Dietary patterns are associated with metabolic risk factors in South Asians living in the United States," The Journal of Nutrition, vol. 145, no. 6, pp. 1211-1217, 2015.

[18] D. Das and A. Haloi, "Vitamin B12 gene polymorphisms and chronic diseases," Journal of Nutritional Disorders \& Theraphy, vol. 4, no. 149, 2014.

[19] S. H. Wild and C. D. Byrne, "Evidence for fetal programming of obesity with a focus on putative mechanisms," Nutrition Research Reviews, vol. 17, no. 02, pp. 153-162, 2004.

[20] S. A. Patel, R. Shivashankar, M. K. Ali et al., "Is the "South Asian phenotype" unique to South Asians?: comparing cardiometabolic risk factors in the CARRS and NHANES studies," Global Heart, vol. 11, no. 1, pp. 89-96.e3, 2016.

[21] A. Misra and U. Shrivastava, "Obesity and dyslipidemia in South Asians," Nutrients, vol. 5, no. 7, pp. 2708-2733, 2013.

[22] L. M. Jaacks, D. Kapoor, K. Singh et al., "Vegetarianism and cardiometabolic disease risk factors: differences between South Asian and US adults," Nutrition, vol. 32, no. 9, pp. 975-984, 2016.

[23] A. Pandey, S. Chawla, and P. Guchhait, "Type-2 diabetes: current understanding and future perspectives," IUBMB Life, vol. 67, no. 7, pp. 506-513, 2015.

[24] U. P. Gujral, K. M. V. Narayan, R. G. Pradeepa et al., "Comparing type 2 diabetes, prediabetes, and their associated risk factors in Asian Indians in India and in the U.S.: the CARRS and MASALA studies," Diabetes Care, vol. 38, no. 7, pp. 1312-1318, 2015.

[25] S. Raj, "The practice of vegetarianism in the South Asian subcontinent," Vegetarian Nutrition Update, vol. XX, no. 1, pp. 15, 2011.

[26] C. L. Ventola, "Current issues regarding complementary and alternative medicine (CAM) in the United States: part 1: the widespread use of CAM and the need for betterinformed health care professionals to provide patient counseling," Pharmacy \& Therapeutics, vol. 35, no. 8, pp. 461-468, 2010.
[27] U. Payyappallimana and P. Venkatasubramanian, "Exploring Ayurvedic knowledge on food and health for providing innovative solutions to contemporary healthcare," Frontiers in Public Health, vol. 4, p. 57, 2016.

[28] K. Patel and K. Srinivasan, "Digestive stimulant action of spices: a myth or reality?," The Indian Journal of Medical Research, vol. 119, no. 5, pp. 167-179, 2004.

[29] K. Srinivasan, "Antioxidant potential of spices and their active constituents," Critical Reviews in Food Science and Nutrition, vol. 54, no. 3, pp. 352-372, 2014.

[30] R. Mathews and R. Zachariah, "Coronary heart disease in South Asian immigrants: synthesis of research and implications for health promotion and prevention in nursing practice," Journal of Transcultural Nursing, vol. 19, no. 3, pp. 292-299, 2008.

[31] B. Lucke-Wold, R. Misra, and T. G. Patel, "Risk factors for low high-density lipoprotein among Asian Indians in the United States," World Journal of Diabetes, vol. 8, no. 6, pp. 297-303, 2017.

[32] J. Anderson, M. Moeschberger, M. S. Chen Jr., P. Kunn, M. E. Wewers, and R. Guthrie, "An acculturation scale for Southeast Asians," Social Psychiatry and Psychiatric Epidemiology, vol. 28, no. 3, pp. 134-141, 1993.

[33] S. N. Walker and D. Hill-Polrecky, "Psychometric evaluation of the health-promoting lifestyle profile-II," in Scientific Session of the American Nurse Association's Council of Nurse Researchers, Washington, D.C., USA, 1996.

[34] C. K. Chow, P. K. Raju, R. Raju et al., "The prevalence and management of diabetes in rural India," Diabetes Care, vol. 29, no. 7, pp. 1717-1718, 2006.

[35] K. R. Kulkarni, "Cholesterol profile measurement by vertical auto profile method," Clinics in Laboratory Medicine, vol. 26, no. 4, pp. 787-802, 2006.

[36] K. G. Alberti, P. Zimmet, and J. Shaw, "Metabolic syndrome-a new world-wide definition. A consensus statement from the international diabetes federation," Diabetic Medicine, vol. 23, no. 5, pp. 469-480, 2006.

[37] Regional Office for the Western Pacific World Health Organization, International Diabetes Institute, International Association for the Study of Obesity, and International Obesity Task Force, The Asia-Pacific Perspective: Redefining Obesity and Its Treatment, Health Communications Australia, Australia, 2000.

[38] I. A. Lesser, D. Gasevic, and S. A. Lear, "The association between acculturation and dietary patterns of South Asian immigrants," PLoS One, vol. 9, no. 2, article e88495, 2014.

[39] N. Abate, M. Chandalia, P. Satija et al., "ENPP1/PC-1 K121Q polymorphism and genetic susceptibility to type 2 diabetes," Diabetes, vol. 54, no. 4, pp. 1207-1213, 2005.

[40] R. Tabassum, A. Mahajan, G. Chauhan et al., "Evaluation of DOK5 as a susceptibility gene for type 2 diabetes and obesity in North Indian population," BMC Medical Genetics, vol. 11, no. 1, p. $35,2010$.

[41] S. P. Bhatt, P. Nigam, A. Misra et al., "Association of the Myostatin gene with obesity, abdominal obesity and low lean body mass and in non-diabetic Asian Indians in North India," PLoS One, vol. 7, no. 8, article e40977, 2012.

[42] R. Tabassum, A. Jaiswal, G. Chauhan et al., "Genetic variant of $A M D 1$ is associated with obesity in urban Indian children," PLoS One, vol. 7, no. 4, article e33162, 2012. 
[43] S. P. Bhatt, P. Nigam, A. Misra et al., "Association of peroxisome proliferator activated receptor- $\gamma$ gene with nonalcoholic fatty liver disease in Asian Indians residing in North India," Gene, vol. 512, no. 1, pp. 143-147, 2013.

[44] J. Kumar, S. K. Das, P. Sharma, G. Karthikeyan, L. Ramakrishnan, and S. Sengupta, "Homocysteine levels are associated with MTHFR A1298C polymorphism in Indian population," Journal of Human Genetics, vol. 50, no. 12, pp. 655-663, 2005.

[45] G. Starkebaum and J. M. Harlan, "Endothelial cell injury due to copper-catalyzed hydrogen peroxide generation from homocysteine," The Journal of Clinical Investigation, vol. 77, no. 4, pp. 1370-1376, 1986.

[46] A. Lim, S. Sengupta, M. E. McComb et al., "In vitro and in vivo interactions of homocysteine with human plasma transthyretin," Journal of Biological Chemistry, vol. 278, no. 50, pp. 49707-49713, 2003.

[47] P. Yi, S. Melnyk, M. Pogribna, I. P. Pogribny, R. J. Hine, and S. J. James, "Increase in plasma homocysteine associated with parallel increases in plasma S-adenosylhomocysteine and lymphocyte DNA hypomethylation," Journal of Biological Chemistry, vol. 275, no. 38, pp. 29318-29323, 2000.

[48] A. R. Devi, V. Govindaiah, G. Ramakrishna, and S. M. Naushad, "Prevalence of methylene tetrahydrofolate reductase polymorphism in South Indian population," Current Science, vol. 86, no. 3, pp. 440-443, 2004.

[49] S. Markan, M. Sachdeva, B. S. Sehrawat, S. Kumari, S. Jain, and M. Khullar, "MTHFR 677 CT/MTHFR 1298 CC genotypes are associated with increased risk of hypertension in Indians," Molecular and Cellular Biochemistry, vol. 302, no. 1-2, pp. 125-131, 2007.

[50] C. S. Yajnik, S. S. Deshpande, H. G. Lubree et al., "Vitamin B12 deficiency and hyperhomocysteinemia in rural and urban Indians," The Journal of the Association of Physicians of India, vol. 54, pp. 775-782, 2006.

[51] R. Misra, P. Balagopal, M. Klatt, and M. Geraghty, "Complementary and alternative medicine use among Asian Indians in the United States: a national study," The Journal of Alternative and Complementary Medicine, vol. 16, no. 8, pp. 843-852, 2010.

[52] M. L. Dansinger, J. A. Gleason, J. L. Griffith, H. P. Selker, and E. J. Schaefer, "Comparison of the Atkins, Ornish, weight watchers, and zone diets for weight loss and heart disease risk reduction: a randomized trial," JAMA, vol. 293, no. 1, pp. 4353, 2005.

[53] A. Izadpanah, R. J. Barnard, A. J. E. Almeda et al., “A shortterm diet and exercise intervention ameliorates inflammation and markers of metabolic health in overweight/obese children," American Journal of Physiology - Endocrinology and Metabolism, vol. 303, no. 4, pp. E542-E550, 2012.

[54] N. Brathwaite, H. S. Fraser, N. Modeste, H. Broome, and R. King, "Obesity, diabetes, hypertension, and vegetarian status among Seventh-Day Adventists in Barbados: preliminary results," Ethnicity \& Disease, vol. 13, no. 1, pp. 34-39, 2003.

[55] E. A. Enas, “Contaminated vegetarianism,” 2007, August 2016, http://www.cadiresearch.org/topic/diet-indian/contaminatedvegetarianism.

[56] S. P. Gupta, "Changes in the food habits of Asian Indians in the United States: a case study," Sociology and Social Research, vol. 60 , no. 1 , pp. 87-99, 1975.
[57] N. Karim, D. S. Bloch, G. Falciglia, and L. Murthy, "Modifications in food consumption patterns reported by people from India, living in Cincinnati, Ohio," Ecology of Food and Nutrition, vol. 19, no. 1, pp. 11-18, 1986.

[58] S. Raj, P. Ganganna, and J. Bowering, "Dietary habits of Asian Indians in relation to length of residence in the United States," Journal of the American Dietetic Association, vol. 99, no. 9, pp. 1106-1108, 1999.

[59] K. M. Azar, E. Chen, A. T. Holland, and L. P. Palaniappan, "Festival foods in the immigrant diet," Journal of Immigrant and Minority Health, vol. 15, no. 5, pp. 953-960, 2013.

[60] P. Kalra, S. Srinivasan, S. Ivey, and K. Greenlund, "Knowledge and practice: the risk of cardiovascular disease among Asian Indians. Results from focus groups conducted in Asian Indian communities in Northern California," Ethnicity \& Disease, vol. 14, no. 4, pp. 497-504, 2004.

[61] S. Arya, S. Isharwal, A. Misra et al., "C-reactive protein and dietary nutrients in urban Asian Indian adolescents and young adults," Nutrition, vol. 22, no. 9, pp. 865-871, 2006.

[62] S. S. Jonnalagadda and S. Diwan, "Regional variations in dietary intake and body mass index of first-generation AsianIndian immigrants in the United States," Journal of the American Dietetic Association, vol. 102, no. 9, pp. 12861289, 2002.

[63] S. S. Jonnalagadda and S. Diwan, "Nutrient intake of first generation Gujarati Asian Indian immigrants in the U.S," Journal of the American College of Nutrition, vol. 21, no. 5, pp. 372-380, 2002.

[64] S. S. Jonnalagadda, S. Diwan, and D. L. Cohen, "U.S. Food Guide Pyramid food group intake by Asian Indian immigrants in the U.S," The Journal of Nutrition, Health \& Aging, vol. 9, no. 4, pp. 226-231, 2005.

[65] J. S. Yudkin, C. S. Yajnik, V. Mohamed-Ali, and K. Bulmer, "High levels of circulating proinflammatory cytokines and leptin in urban, but not rural, Indians. A potential explanation for increased risk of diabetes and coronary heart disease," Diabetes Care, vol. 22, no. 2, pp. 363-364, 1999.

[66] R. Misra, A. Misra, N. Kamalamma et al., "Difference in prevalence of diabetes, obesity, metabolic syndrome and associated cardiovascular risk factors in a rural area of Tamil Nadu and an urban area of Delhi," International Journal of Diabetes in Developing Countries, vol. 31, no. 2, pp. 82-90, 2011.

[67] A. Misra, L. Khurana, S. Isharwal, and S. Bhardwaj, "South Asian diets and insulin resistance," British Journal of Nutrition, vol. 101, no. 4, pp. 465-473, 2009.

[68] R. Green, J. Milner, E. J. M. Joy, S. Agrawal, and A. D. Dangour, "Dietary patterns in India: a systematic review," British Journal of Nutrition, vol. 116, no. 01, pp. 142-148, 2016.

[69] B. L. Pierce, M. A. Austin, P. K. Crane et al., "Measuring dietary acculturation in Japanese Americans with the use of confirmatory factor analysis of food-frequency data," The American Journal of Clinical Nutrition, vol. 86, no. 2, pp. 496-503, 2007.

[70] N. Watanabe, Y. Watanabe, M. Kumagai, and K. Fujimoto, "Administration of dietary fish oil capsules in healthy middle-aged Japanese men with a high level of fish consumption," International Journal of Food Sciences and Nutrition, vol. 60, Supplement 5, pp. 136-142, 2009.

[71] C. H. Tsunehara, D. L. Leonetti, and W. Y. Fujimoto, "Diet of second-generation Japanese-American men with and without 
non-insulin-dependent diabetes," The American Journal of Clinical Nutrition, vol. 52, no. 4, pp. 731-738, 1990.

[72] D. Ornish, L. W. Scherwitz, J. H. Billings et al., "Intensive lifestyle changes for reversal of coronary heart disease," JAMA, vol. 280, no. 23, pp. 2001-2007, 1998.

[73] E. Enas and A. Senthilkumar, "Coronary artery disease in Asian Indians: an update and review," Internet Journal of Cardiology, vol. 1, no. 2, pp. 1-57, 2001.

[74] S. Tonstad, T. Butler, R. Yan, and G. E. Fraser, "Type of vegetarian diet, body weight, and prevalence of type 2 diabetes," Diabetes Care, vol. 32, no. 5, pp. 791-796, 2009.

[75] V. Mohan, S. Shanthirani, R. Deepa et al., "Intra-urban differences in the prevalence of the metabolic syndrome in Southern India - the Chennai Urban Population Study (CUPS no. 4)," Diabetic Medicine, vol. 18, no. 4, pp. 280-287, 2001.

[76] C. M. Rebholz, D. C. Crews, M. E. Grams et al., "DASH (Dietary Approaches to Stop Hypertension) diet and risk of subsequent kidney disease," American Journal of Kidney Diseases, vol. 68, no. 6, pp. 853-861, 2016.

[77] E. J. McMahon, K. L. Campbell, J. D. Bauer, and D. W. Mudge, "Altered dietary salt intake for people with chronic kidney disease," Cochrane Database of Systematic Reviews, vol. 2, article CD010070, 2015.

[78] E. Mostofsky, K. J. Mukamal, E. L. Giovannucci, M. J. Stampfer, and E. B. Rimm, "Key findings on alcohol consumption and a variety of health outcomes from the Nurses' health study," American Journal of Public Health, vol. 106, no. 9, pp. 15861591, 2016.

[79] F. Huang, J. Zhang, H. Wang et al., "Effect of dietary cholesterol intake on stroke incidence among Chinese adults: evidence from China health and nutrition survey," Wei Sheng Yan Jiu, vol. 45, no. 3, pp. 383-387, 2016.

[80] L. B. Morgenstern, B. N. Sánchez, K. M. Conley et al., "The association between changes in behavioral risk factors for stroke and changes in blood pressure," Journal of Stroke and Cerebrovascular Diseases, vol. 25, no. 9, pp. 2116-2121, 2016.

[81] A. Perez-Cornago, A. Sanchez-Villegas, M. Bes-Rastrollo et al., "Relationship between adherence to dietary approaches to stop hypertension (DASH) diet indices and incidence of depression during up to 8 years of follow-up," Public Health Nutrition, vol. 20, no. 13, pp. 2383-2392, 2017.

[82] A. Salehi-Abargouei, Z. Maghsoudi, F. Shirani, and L. Azadbakht, "Effects of dietary approaches to stop hypertension (DASH)-style diet on fatal or nonfatal cardiovascular diseases-incidence: a systematic review and meta-analysis on observational prospective studies," Nutrition, vol. 29, no. 4, pp. 611-618, 2013.

[83] L. Borgi, I. Muraki, A. Satija, W. C. Willett, E. B. Rimm, and J. P. Forman, "Fruit and vegetable consumption and the incidence of hypertension in three prospective cohort studies," Hypertension, vol. 67, no. 2, pp. 288-293, 2016.

[84] E. M. Alissa and G. A. Ferns, "Dietary fruits and vegetables and cardiovascular diseases risk," Critical Reviews in Food Science and Nutrition, vol. 57, no. 9, pp. 1950-1962, 2017.

[85] N. C. Tan, K. H. Koh, C. C. Goh, Y. L. E. Koh, and S. C. P. Goh, "Asian patients with dyslipidemia in an urban population: effect of ethnicity on their LDL-cholesterol treatment goals," Journal of Clinical Lipidology, vol. 10, no. 2, pp. 410-419, 2016.

[86] D. Anthony, R. Baggott, J. Tanner et al., "Health, lifestyle, belief and knowledge differences between two ethnic groups with specific reference to tobacco, diet and physical activity,"
Journal of Advanced Nursing, vol. 68, no. 11, pp. 2496-2503, 2012.

[87] N. R. Ghai, S. J. Jacobsen, S. K. Van Den Eeden et al., “A comparison of lifestyle and behavioral cardiovascular disease risk factors between Asian Indian and White non-Hispanic men," Ethnicity \& Disease, vol. 22, no. 2, pp. 168-174, 2012.

[88] A. Vigneswari, R. Manikandan, K. Satyavani, S. Archana, R. Rajeswari, and V. Viswanathan, "Prevalence of risk factors of diabetes among urban poor South Indian population," The Journal of the Association of Physicians of India, vol. 63, no. 10, pp. 32-34, 2015. 


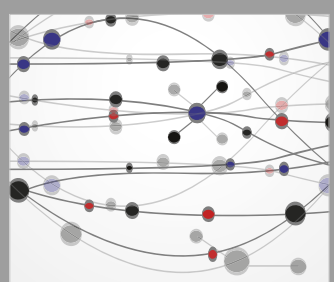

The Scientific World Journal
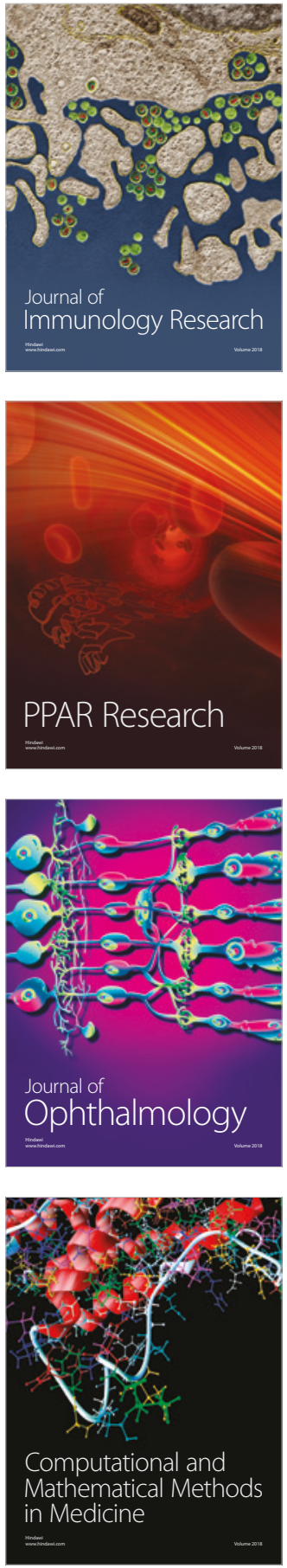

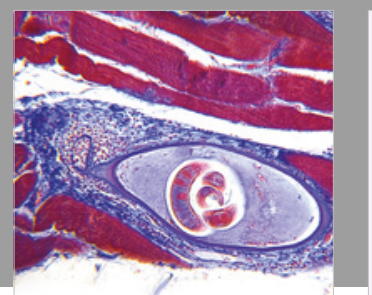

Gastroenterology Research and Practice

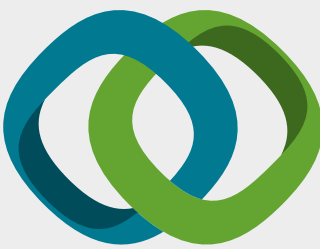

\section{Hindawi}

Submit your manuscripts at

www.hindawi.com
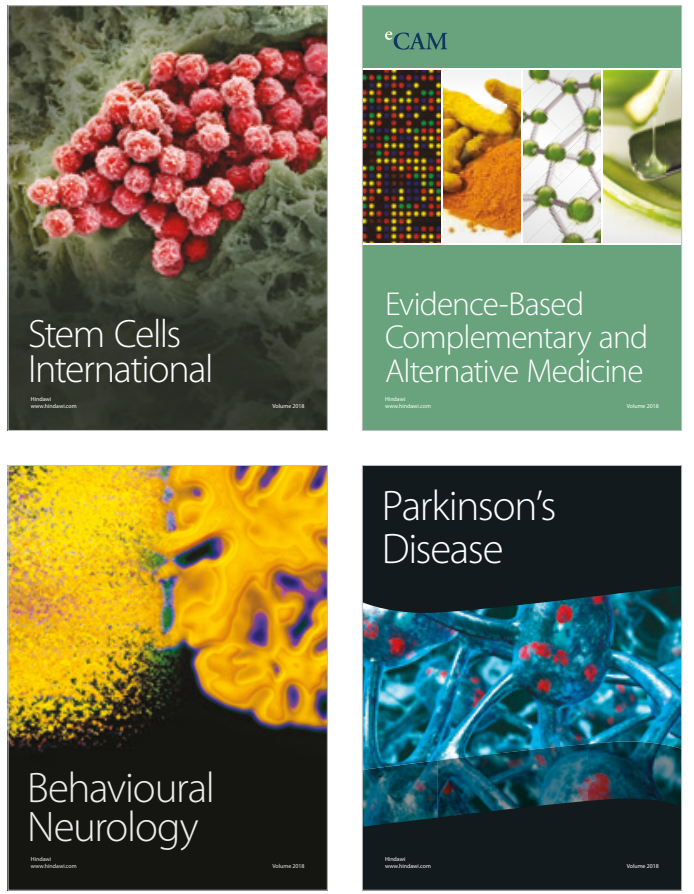

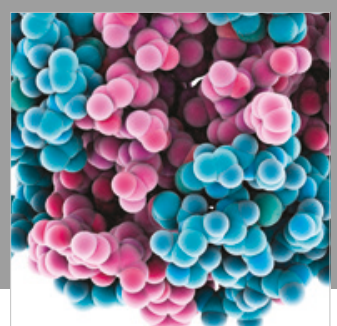

ournal of

Diabetes Research

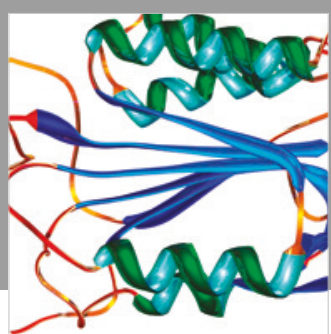

Disease Markers
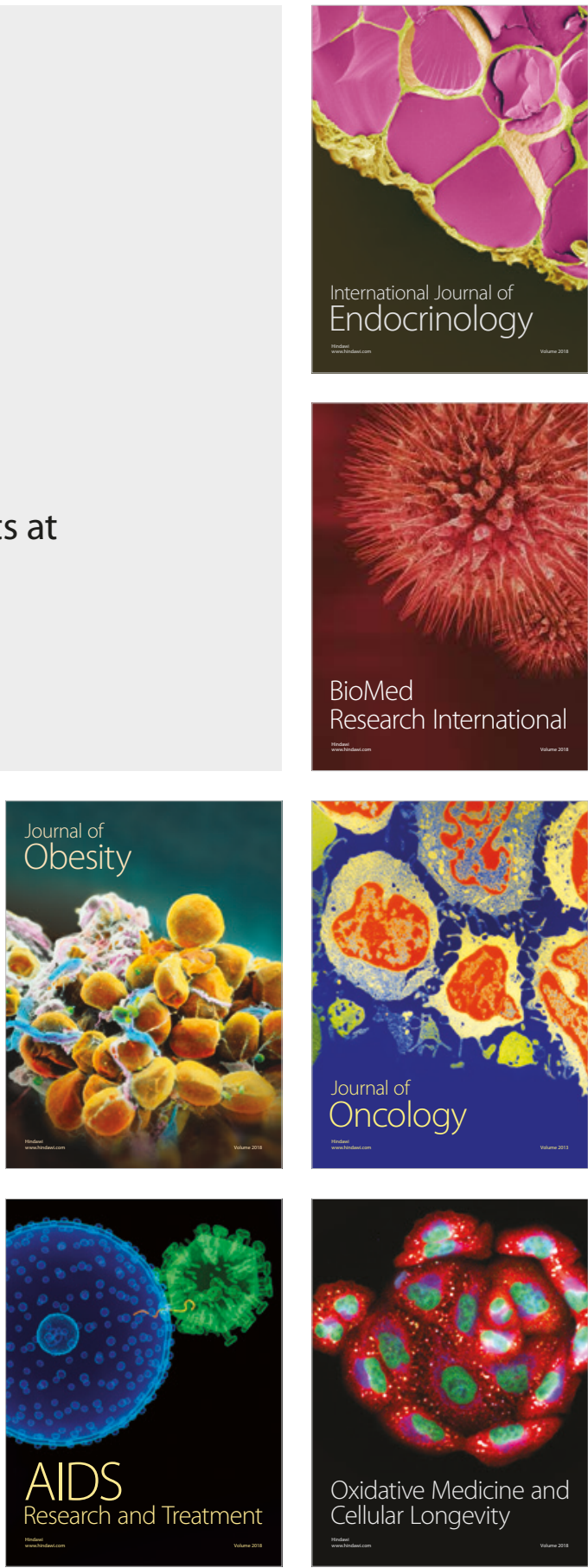